\title{
A NOÇÃO DE DUPLO E SUA IMPORTÂNCIA NA DISCUSSÃO DO AUTISMO
}

\author{
Ana Ramyres Andrade de Araújo, Luis Achiles Rodrigues Furtado \\ e Samara Fernandes Paiva dos Santos \\ Ana Ramyres Andrade \\ de Araújo \\ Universidade \\ Federal do Ceará \\ (UFC), Mestranda \\ do Departamento \\ de Psicologia, \\ Sobral/CE, Brasil. \\ Luis Achiles Rodrigues \\ Furtado \\ Universidade \\ Federal do Ceará \\ (UFC), Professor do \\ Departamento de \\ Psicologia, Sobral/ \\ RESUMO: Este trabalho tem o apoio da Fundação Cearense de Apoio \\ ao Desenvolvimento Científico e Tecnológico (Funcap); é parte \\ de nossa pesquisa Sujeito e indivíduo: uma análise dos materiais audiovisuais \\ e autobiográficos de pessoas autistas e suas contribuições para o campo de interface \\ entre a educação inclusiva e a clínica psicanalítica. Através de uma revisão \\ bibliográfica, aborda a noção de duplo a partir do texto freudiano \\ O estranho (1919). Recorremos também às considerações de Maleval \\ (2011) sobre o tema do duplo e o autismo. Conclui-se que a noção \\ de duplo apresenta-se como importante ferramenta na clínica e na \\ educação de autistas.
}

CE, Brasil.

Palavras-chave: psicanálise; duplo; autismo.

Samara Fernandes Paiva dos Santos

Universidade

Federal do Ceará

(UFC), Graduada

pelo Departamento

de Psicologia,

Sobral/CE, Brasil.

ABSTRACT: The notion of double and its importance in the discussion of autism. This work is supported by the Ceará Foundation for Scientific and Technological Development (Funcap) and is part of our research Subject and the individual: an analysis of audiovisual and autobiographical materials of autistic people and their contributions to the field of interface between inclusive education and psychoanalytic clinic. Through a literature review, discusses the notion of double from the Freudian text The Uncanny (1919). Recourse also to considerations of J. C. Maleval (2011) on the theme of double and autism. We conclude that the notion of double presents itself as an important tool in clinical and education of autistic.

Keywords: psychoanalysis; double; autism. 


\section{INTRODUÇÃOO}

O presente artigo é parte de nossa pesquisa que conta com o apoio da Fundação Cearense de Apoio ao Desenvolvimento Científico e Tecnológico (Funcap), e trata da noção de duplo em psicanálise tendo como ponto de partida o texto $\mathrm{O}$ estranho, publicado por Freud em 1919, no qual ele analisa o conto O homem da areia de E. T. A. Hoffman. Este retorno ao texto freudiano é importante na medida em que abre espaço para questões pertinentes a nossa discussão. Em seguida, abordaremos as considerações de J. C. Maleval (2009/2011) em seu livro El altista y su voz além de outras publicações do mesmo autor, sobre a aproximação possível entre o tema do duplo e do autismo, de que trata a psicanálise.

Este tema apresenta-se como essencial aos nossos estudos por ter grande relevância no campo teórico-prático, principalmente no que se refere à nossa pesquisa em andamento, que visa contribuir para o campo de interface entre a clínica psicanalítica e a educação inclusiva através da análise de produções autobiográficas e audiovisuais de autistas e sua confrontação com as concepções teórico-metodológicas dos principais autores psicanalistas de orientação lacaniana.

Frente aos inúmeros posicionamentos dos autores de referência, buscamos discutir o que se tem produzido, e trazer contribuições para a temática da educação inclusiva especificamente no que se refere ao autismo. Desse modo, a pesquisa bibliográfica se configura como uma importante ferramenta com a qual é possível o estudo e revisão da literatura psicanalítica acerca do autismo, seus impasses, limites e, além disso, a fundamentação, ainda que inicial, de nosso próprio posicionamento a respeito do tema e seus desdobramentos.

Ao longo do texto, algumas questões se destacam no que se refere à possibilidade de a criança autista esboçar, por meio do duplo, uma forma de relação com a alteridade de modo que o estabelecimento do laço social proporcione, além de alternativas de ciframento do gozo, uma série de possibilidades de inserção em espaços e papéis por meio de uma enunciação que lhe seja mais suportável.

Portanto, é imprescindível que a escola seja mais um desses espaços, no qual a criança, ainda que diagnosticada com autismo, não deixe de ser vista como sujeito, e que possa esboçar modos específicos de relação com seus semelhantes, usufruindo das possibilidades que o ambiente escolar pode lhe proporcionar.

Uma compreensão adequada acerca do autista tem sido discutida com bastante notoriedade por famílias, especialistas e profissionais das áreas da saúde e educação - embora muitas dificuldades ainda existam e sejam necessários mais estudos que proporcionem não só soluções, mas também novos pontos de debate. Ações provenientes de secretarias e instâncias governamentais visam regulamentar e estabelecer parâmetros para as questões que surgem no que se refere aos autistas e aos serviços a eles destinados. 
Nesse cenário, apontamos a importância das contribuições da psicanálise, que se debruça sobre as questões centrais do sujeito, na particularidade em que se enuncia. Ao considerar sua singularidade — não o compreendendo apenas como um portador de rótulos, de significantes mestres - reafirma, no que se refere aos autistas, que é necessário supor ali um sujeito, para além das limitações e dificuldades decorrentes da associação do autismo a déficits e complicações relacionadas à linguagem, psicomotricidade e outros. E que este possui também um modo peculiar de lidar com os campos do Outro, da linguagem, do gozo e da falta.

Portanto, faz-se necessário um trabalho teórico de revisão inicial sobre o tema do duplo em Freud, considerando as referências teóricas com as quais propomos realizar a revisão bibliográfica. Freud, por sua vez, toma como aspectos centrais do texto o conto no qual reúne considerações importantes sobre a noção de duplo. Tendo em vista os aspectos peculiares do conto, sobre os quais o autor tece considerações importantes para nosso estudo, temos como base para análise as diversas gradações apontadas no processo que se refere ao duplo.

É possível, então, que haja uma aproximação entre o duplo e o autismo, no tocante à dimensão da alteridade? Esse e outros questionamentos são considerados ao longo do texto a partir das referências já mencionadas e outras que julgamos relevantes à discussão. Quanto ao diálogo entre psicanálise e arte (neste caso, o conto), é importante esclarecer que a psicanálise não se debruça sobre a arte como um terreno onde aplicar suas teorias, mas aborda a verdade inconsciente sobre o desejo, descoberta a partir da clínica, da qual as obras literárias e artísticas se aproximariam mais rapidamente do que a ciência.

\section{O HOMEM DA AREIA: UMA LEITURA FREUDIANA}

Freud (1919/1986) aponta duas formas pelas quais o tema do estranho poderia ser estudado. A primeira forma consiste em analisar as noções que a palavra Unheimlich tem em diversas línguas, pesquisando o desenvolvimento dos significados em torno desta. A segunda maneira seria agrupar tudo o que desperta os sentimentos do estranho e partir, então, de algo comum a todos eles de forma a evidenciar o que permanece.

Quanto à primeira maneira, o autor analisa os desenvolvimentos de Unheimlich na língua alemã, na língua francesa e na língua inglesa e traz também seus usos em obras literárias conhecidas, evidenciando o que esta palavra possui de contraditória. Em ambos os caminhos, o que pode ser encontrado sobre o estranho relaciona-se com o que é assustador e ao mesmo tempo conhecido, familiar (FREUD, 1919/1986, p. 220-223). 
O significado da palavra Heimlich, muitas vezes usada no sentido de familiar, coincide com Unheimlich, seu oposto. A partícula “un” é apontada por Freud como uma indicação da ação do recalque, sendo assim uma palavra de significado ambivalente. Como afirma: “Então, Heimlich é um palavra que tem desenvolvido seu significado seguindo uma ambivalência até coincidir ao fim com seu oposto, unheimlich. De algum modo, Unheimlich é uma variedade de Heimlich” (FREUD, 1919/1986, p. 224).

No conto analisado um dos detalhes do efeito do estranho é a aparência estranha da boneca Olímpia. Esta, embora seja um autômato, é tomada por Natanael (personagem principal) como a mais bela das mulheres. A estranheza em relação à Olímpia — aponta Freud — não é o único fator pelo qual se atribui o efeito de estranho; antes, é a representação de ser despojado dos olhos pelo homem da areia, extremamente insuportável e que pode ser considerada um substituto frente à angústia de castração.

A boneca Olímpia é apontada como um desprendimento de Natanael. Olímpia lhe sai como pessoa por outro lado é uma materialização da atitude feminina dele frente ao seu par de pais que Hoffman (1815/1978) apresenta ao leitor na infância da personagem o homem da areia — o que quer tirar-lhe os olhos - e o pai do estudante que o defende desta ameaça. Na juventude, a imago paterna é reeditada: o ótico Coppola é identificado com o Coppelius e o professor Spalanzani — pai e construtor de Olímpia — identifica-se à imagem do pai de Natanael.

Compreende-se assim o amor sem restrições que o próprio Natanael demonstrou à boneca: “Temos direito a chamar 'narcisista' a este amor, e compreendemos que sua vítima se aliena do objeto real de amor"1 (FREUD, 1919/1986, p. 232).

O leitor não sabe ao certo se alguns acontecimentos de fato são reais ou somente fantasias construídas pelo personagem principal, Natanael. Ainda assim, a indicação no final do conto de que o ótico Coppola é o advogado Coppelius — o homem da areia — não é o suficiente para retirar o efeito do estranho. O que está em jogo relaciona-se não com o despertar de uma antiga angústia infantil, mas de um desejo ou de uma crença infantil.

Freud menciona ainda alguns motivos pelos quais temos o efeito do estranho no conto e que nos auxiliam na compreensão do duplo em sua relação com o que é infantil:

Há aqui: a presença do duplo em todas as suas gradações de desenvolvimento, vale dizer, a aparição de pessoas que por seu idêntico aspecto devem considerar-se idênticas; o acréscimo desta circunstância pelo salto de processos anímicos de uma

\footnotetext{
1 "Tenemos derecho a llamar 'narcisista' a este amor, e comprendemos que su víctima se enajene del objeto real de amor."
} 
dessas pessoas a outra — o que chamaríamos telepatia — , de sorte que um possui o conhecimento, o sentir e o vivenciar do outro; a identificação com outra pessoa até o ponto de equivocar-se sobre o próprio eu ou situar o seu eu alheio no lugar do próprio - ou seja, duplicação, divisão, permutação do eu — e por último, o permanente retorno do igual (... $)^{2}$ (FREUD, 1919/1986, p. 234).

Esta indicação merece uma análise mais detalhada, pois nela podemos verificar as várias gradações que o duplo pode ter, desde um momento inicial até o que chamaríamos mais complexo no tocante à alteridade.

O primeiro momento seria um esboço de identificação baseada na suposição de que ambas as pessoas partilham de um mesmo aspecto. Consideremos neste ponto que a possível relação entre o duplo e a imagem de algo ou de alguém idêntico a si mesmo — ou ainda o reflexo no espelho e o que visivelmente é igual em atributos e características — se configura como importante na constituição do eu na medida em que possibilita a construção dos limites corporais, das bordas que separam o que faz e o que não faz parte do eu, portanto, da sua afirmação como sujeito.

Logo, podemos destacar o que Freud afirma em O eu e o isso (1923/1992, p. 28): "Ou seja, que o eu deriva em última instância de sensações corporais, principalmente as que partem da superfície do corpo. Cabe considerá-lo, então, como a projeção psíquica da superfície corporal (...)”3.

Soma-se a esse primeiro ponto a certeza de que se compartilham aspectos íntimos e particulares com o outro tais como os sentimentos, emoções e pensamentos. Nesse segundo momento, destaca-se a importância do olhar de reconhecimento lançado pelo outro em direção ao infans. O grito e o choro, antes no plano da necessidade e decorrentes de um desconforto, quando considerados pelo outro como apelo já não são simples gritos e barulhos, mas, sim, demanda.

Em um terceiro momento, a identificação propriamente dita caracteriza-se então pelo fato de uma das pessoas situarem seu eu no eu do outro, ou seja, há uma divisão do eu. Por último, o quarto momento desse conjunto de gradações

\footnotetext{
2 "Helos aquí; la presencia de «dobles» en todas sus gradaciones y plasmaciones, vale decir, la aparición de personas que por su idéntico aspecto deben considerarse idénticas; el acrecentamiento de esta circunstancia por el salto de procesos anímicos de una de estas personas a la otra - lo que llamaríamos telepatia — , de suerte que uma es coposeedora del saber, el sentir y el vivenciar de la otra; la identificación con otra persona hasta el punto de equivocarse sobre el propio yo o situar el yo ajeno en el lugar del propio — o sea, duplicación, división, permutación del yo —, y, por ultimo, el permanente retorno de lo igual (...)."

3 "O sea que el yo deriva en última instancia de sensaciones cor-perales, principalmente las que parten de la superficie del cuerpo. Cabe considerarlo, entonces, como la proyección psíquica de la superfície del cuerpo, además de representar, como se ha visto antes, la superficie del aparato psíquico."
} 
apresentadas pelo duplo: o retorno do que foi considerado igual. A busca por outros objetos - que supostamente possuem traços com os quais houve uma identificação anterior é extremamente importante no que se refere à formação de laço social.

Esse investimento libidinal em outros objetos implica em certa medida em um empobrecimento — sob o ponto de vista econômico — do investimento que se observa no narcisismo primário presente nas primeiras das quatro gradações apresentadas anteriormente. Como afirma Freud no texto Introdução ao narcisismo:

O desenvolvimento do eu consiste em um distanciamento se comparado ao narcisismo primário e engendra uma intensa aspiração a recobrá-lo. Este distanciamento acontece por meio do deslocamento da libido a um ideal do eu imposto de fora; a satisfação é obtida mediante o cumprimento deste ideal. Simultaneamente, o eu tenha emitido os investimentos libidinais de objeto (... ${ }^{4}$. (FREUD, 1914/1975, p. 96-97)

Encontramos no parágrafo seguinte outra indicação importante acerca da relação entre o eu e os objetos: "Uma parte do sentimento de si é primária, o resíduo do narcisismo infantil; outra parte provém da onipotência corroborada pela experiência (o cumprimento do ideal do eu), e uma terceira, da satisfação da libido objetal"5 (FREUD, 1914/1975, p. 97).

Portanto, o duplo seria, sim, um momento inicial de investimento em si, necessário para que haja um investimento posterior em outros objetos de amor, bem como a satisfação ou insatisfação decorrente deles.

Cabe a pergunta: em qual gradação o duplo autístico se encontra? Ou ainda: se este não pode ser identificado com nenhum dos momentos anteriormente mencionados, como intervir de modo que sejam dadas as condições e possibilidades de uma construção da relação com um duplo, segundo as peculiaridades que cada uma das crianças traz? Outras indicações parecem nos auxiliar nessa questão.

Em sua origem, o duplo foi uma segurança contra o aniquilamento do eu e é provável que o primeiro duplo do corpo tenha sido a alma imortal. Em outros termos, uma defesa contra o aniquilamento subjetivo. Seguindo as palavras de Freud, essas representações referem-se ao amor sem restrições por si — como vimos, o narcisismo primário - emarca mudanças totalmente opostas.

\footnotetext{
4 "El desarrollo del yo consiste en un distanciamiento respecto del narcisismo primario y engendra una intensa aspiración a recobrarlo. Este distanciamiento acontece por médio del desplazamiento de la libido a un ideal del yo impuesto desde fuera; la satisfacción se obtiene mediante el cumplimiento de este ideal. Simultáneamente, el yo ha emitido las investiduras libidinosas de objeto."

5 “Una parte del sentimiento de sí es primaria, el residuo del narcisismo infantil; otra parte brota de la omnipotencia corroborada por la experiencia (el cumplimiento del ideal del yo), y una tercera, de la satisfacción de la libido de objeto."
} 
Com a superação do narcisismo primário, o signo do duplo modifica-se. Se, num primeiro momento, seria uma garantia de segurança, atitude de desmentido radical frente à morte, num tempo posterior configuraria a presentificação da própria morte. De acordo com Freud (1919/1986, p. 235), “A representação do duplo não necessariamente é sepultada junto com esse narcisismo inicial; de fato, pode cobrar um novo conteúdo a partir dos posteriores estágios de desenvolvimento do eu"6.

O estranho proveniente de uma vivência se produz quando os complexos infantis recalcados são reafirmados, reanimados por uma impressão posterior. O duplo apresenta-se como esse eu no qual é possível reconhecer-se, mas que demonstra vir de outro, e, muitas vezes pode ser invasivo. No decorrer do desenvolvimento do eu, essas representações formam uma instância particular que se volta para este, tratando-o como objeto. Ela é marcada pela autocrítica, pela censura psíquica e uma consciência moral que visa observar e criticar o eu. Posteriormente, Freud (1923-1924) a chamará de Supereu.

Enquanto sujeito dotado da capacidade de observar-se, é possível preencher a antiga representação do duplo com novos conteúdos, todas as possibilidades de apreensão, as aspirações do eu que não puderam realizar-se e, principalmente, tudo o que se refere à autocrítica pertencente ao narcisismo primário superado.

Freud afirma:

Então, o caráter do estranho só pode residir no que o duplo é uma formação oriunda das épocas primordiais da alma já superadas, que naquele tempo possuiu sem dúvida um sentido mais benigno. ${ }^{7}$ (FREUD, 1919/1986, p. 236)

Esta última indicação de Freud se mostra interessante na medida em que podemos refletir sobre o caráter fundamental do duplo na constituição do eu ou, ainda, o apaziguamento frente à possibilidade de destruição do eu. Como pensar a mudança que pode ocorrer passando de um duplo caracterizado pela função de proteção para um duplo caracterizado por uma dimensão aterrorizante? Se as possibilidades de representação do duplo são muitas e não necessariamente unívocas, ou seja, podem adquirir outros conteúdos, as representações não necessariamente seriam sepultadas junto com o narcisismo primário. Isto nos

\footnotetext{
6 "La representación del doble no necesariamente es sepultada junto con ese narcisismo inicial; en efecto, puede cobrar un nuevo contenido a partir de los posteriores estadios de desarrollo del yo."

7 “Entonces, el carácter de lo ominoso solo puede estribar en que el doble es una formación oriunda de las épocas primordiales del alma ya superadas, que en aquel tiempo poseyó sin duda un sentido más benigno."
} 
autoriza a pensar no duplo e sua relação com o autismo a partir dessas indicações iniciais de Freud.

Diante dessa observação, algumas questões ainda persistem: de que maneira podemos relacionar o tema do duplo em Freud e com o que se entende por autismo à luz da psicanálise? Que elementos em comum podem ou não ser apontados? Já percorremos alguns pontos, mas convém abordar o tema do autismo com mais detalhes. É vasta a literatura sobre o autismo, principalmente entre autores cujo referencial é a psicanálise de orientação lacaniana. Suas considerações giram em torno de conceitos fundamentais e sua relação com o autismo, além de intervenções orientadas por esta.

Uma pergunta é válida no que se refere à intervenção: seria o duplo uma época primordialmente importante para que se estabeleça uma relação posterior não menos problemática mas ainda assim importante com a alteridade? E se primordialmente o duplo teria um caráter mais benigno, estaria aí o duplo autístico?

Para avançarmos, faremos algumas considerações sobre as indicações de Maleval (2009/2011) no livro El altista y su voz e em outras publicações. O autor não é o único a mencionar a importância de se pensar a relação destes dois elementos, principalmente na clínica do autismo, num momento em que, apesar de seus mais de 70 anos de "invenção", o autismo continua a ser fonte de muitas questões.

\section{O TEMA DO DUPLO NA LEITURA DE JEAN-CLAUDE MALEVAL}

De acordo com Maleval (2009/2011), na clínica do autismo, evidencia-se que a criança autista é de fato cindida entre sua dimensão afetiva e seu intelecto; o seu gozo é enlouquecido e sem ciframento significante, ou seja, não é regulado pelo simbólico. A compreensão acerca do papel regulador e comunicativo da linguagem é, por vezes, tardia; os outros, por sua vez, podem lhe parecer inquietantes e incomodamente imprevisíveis.

A sobrecarga de gozo pode resultar em um sistema nervoso hiperativo. Há uma tentativa constante de dominar "demasiada energia”, e o esforço nesse sentido tem o objetivo de desviar o gozo do corpo à sua própria segurança e defesa. Com esse intuito, o autista se dedica a criar uma borda que o separa do mundo caótico, confinando-o ao seu mundo povoado de objetos, controlado e seguro, protegendo-se assim do Outro real e invasor.

Neste ponto, podemos fazer um questionamento sobre a importância da borda, tanto no que se refere à constituição do eu quanto especificamente à borda autística. Seria a borda que Maleval aponta como central no autismo uma tentativa, um esboço, em busca da efetivação do eu, enquanto projeção psíquica de uma superfície corporal, como diz Freud anteriormente? Uma vez que superfície também pode ser entendida como uma zona limítrofe, separando o "eu” e o 
“não-eu”, tal como aponta Freud no texto A negativa (1925/1992), pode-se entender a borda também como uma tentativa, ainda que inicial, de circunscrição do eu?

Por outro lado, Maleval afirma que a recusa e esquiva dos objetos reais tais como a voz, o olhar, o objeto oral (este é possível observar nos frequentes casos de "transtorno alimentar" relacionado aos autistas) e a dificuldade em manter a limpeza e higiene relacionadas ao objeto anal são indicações de que se estabelece uma relação específica com esses quatro objetos pulsionais e com os demais. E, por vezes, permeada não só pela recusa de sua queda, mas também pela imutabilidade de outros elementos de seu entorno, o que lhe garantiria maior segurança:

Todos esses objetos reais são para ele [o autista] angustiantes, sua presença desperta o risco de uma perda insuportável. Por isso a construção de uma realidade compatível com as demais passa por integrá-los à sua borda autística. (MALEVAL, 2009/2011, p. 96)

Em alguns autistas, o comportamento de fronteira é apontado como uma concretização dessa borda. Há outros autores que também versam sobre este aspecto. Dentre eles, Éric Laurent em Autismo e psicanálise (1992), onde afirma ser o retorno do gozo a uma borda uma das características fundamentais do autismo. Esse retorno seria um dos aspectos diferenciais do autismo em relação à síndrome esquizofrênica (em que o gozo retorna no corpo) e à síndrome paranoica (em que ele retorna no Outro).

Conforme Maleval:

A borda da criança autista pode ser uma barreira autoerótica gerada por estimulações corporais, tais como movimentos, balanceios, pressão sobre os olhos, etc., que separam sua realidade perceptiva do mundo exterior quando este se torna muito insistente (...). (MALEVAL, 2009/2011, p. 97)

Podem ser formados ao longo do desenvolvimento dessa borda protetora o que o autor chama de três "pseudópodes", em certa medida interdependentes: as ilhas de competência, os objetos autísticos ea imagem do duplo. No que se refere às ilhotas de competência e os objetos autísticos, não representam meras “obsessões”. Se consideradas empecilhos e necessariamente extirpáveis, a separação do autista e suas preferências por determinados objetos e assuntos seriam então motivo de sofrimento e incômodo extremos. Tais objetos podem ser muito úteis no desenvolvimento de habilidades e apaziguamento da angústia, além de possibilitarem reconhecimento e construção de laço social.

Além do retorno de gozo a uma borda, a retenção do objeto vocal, que acarretaria um tratamento diferencial da linguagem, é uma das constantes apontadas 
pelo autor. Ao sair do mutismo, o sujeito pode apresentar uma das seguintes formas de lidar com o objeto vocal: ou o autista fala por meio de uma voz verbosa, cujas palavras não formam uma cadeia de significantes(e, portanto, não estabeleça laço social), ou ele utiliza uma voz factual, sem variantes que denotariam algum tipo de enunciação. Esta última quase sempre é suportada por outro objeto, ou seja, é esse objeto que fala, não o próprio autista (MALEVAL, 2010, p. 4).

Na relação entre a criança autista e um duplo, podemos destacar que este último caracteriza-se principalmente por não ser um objeto estranho e maléfico em relação ao sujeito e, sim, familiar, permitindo a ele, o autista, utilizar-se de seus recursos até mesmo de partes do corpo de uma pessoa para obter o que é necessário e evitar, assim, qualquer sinal de enunciação ou pedido (MALEVAL, 2009/2011, p. 98).

O estabelecimento de uma conexão entre a libido localizada em sua borda e onde ela, a libido, está caótica é essencial nesses momentos. É sobre esse duplo - estrutura na qual a criança autista pode sair de sua solidão, apoiando-se em sua possibilidade de receber um gozo sem ciframento - que está situado o essencial do gozo não entrelaçado, em um estado de profunda dependência.

O que nos evoca as considerações de Freud, pois este aponta uma gradação de desenvolvimento na qual o eu pode confundir-se com o eu do duplo, atribuindo-lhe todos os direitos sobre as decisões mais simples, sobre os estados de humor e de saúde. Um exemplo trazido no livro é o caso de Peter e sua terapeuta Mira Rotherberg (MALEVAL, 2009/2011, p. 99).

Quanto à permutação e divisão do eu, é interessante notar os chamados “companheiros de Donna Williams”, um dos exemplos mais citados por Maleval. Para dar consistência ao seu eu, Donna desenvolveu "personagens" que a ajudavam a comunicar-se com os outros. Essa relação com a alteridade só era possível através de Willie e Carol, as duas personagens construídas por ela.

A primeira encarnava sua agressividade extrema e sua rebeldia. Willie é descrita por Donna como uma personalidade extremamente furiosa, que procurava sempre manter os outros sobre seu inteiro domínio e, para isso, apresentava argumentos sólidos e consistentes. Conta ainda: "Era uma criatura de olhar aceso de ódio, com os lábios apertados, os punhos cerrados, com uma postura de rigidez cadavérica (...)” (WILLIAMS apud MALEVAL, 2009/2011, p. 105).

Maleval segue afirmando que Donna considera favorável o desenvolvimento de Willie, pois teve enormes ganhos com sua ajuda, que a fez esboçar inicialmente sua independência e capacidade argumentativa — ainda que jamais defendesse um ponto de vista específico, apenas interessava-lhe ser persuasiva o bastante em qualquer argumento - , além de ser importante para a função de proteção em relação ao mundo externo, embora permitisse, em certa medida, um contato com os demais ao seu redor. 
Já Carol tem a mesma estrutura que Willie, mas de forma inversa. Representava sua sociabilidade e bons modos. Sua aparência, os traços que lhe eram diferentes em relação à Willie eram parecidos com as características próprias de Donna, de modo que seus reflexos se confundiam com esta última.

O autor assinala que, assim como Willie, Carol fora construída a partir de significantes provenientes da mãe de Donna, encarnando os ideais maternos nela investidos. O contato com os outros se dava com a ajuda de Carol, sob a condição de que os sentimentos pessoais, ou seja, a própria Donna — fossem apagados na enunciação; os conteúdos das conversas não poderiam ser considerados pertencentes a ela.

Segundo Maleval (2009/2011, p. 99), ao contrário do que ocorre na psicose, o duplo autístico não é ameaçador e invasor, pois a própria criança o escolheu e o mantém, modificando-o. Dessa forma, o duplo se configura como um recurso extremamente interessante, pois pode auxiliar nas tentativas de apaziguamento, como suporte que dá consistência a um eu ideal, ou o oposto das características específicas do eu, tal como as personalidades de Donna Williams.

Em alguns autistas, dentre eles Donna mencionada anteriormente, o duplo se integra ao próprio eu, permitindo que eles se comuniquem com os outros, ainda que não seja sujeito de sua enunciação. Para Donna, uma única condição em que se podia esboçar certa comunicação com outras pessoas a fim de transmitir-lhes um pouco do que se passava em seu mundo seria por meio de espetáculos que ela mesma organizava. Maleval (2009/2011, p. 107) salienta: "Donna não trata de representar [nos espetáculos e peças teatrais] a divisão artificial produzida entre ela e Carol. O duplo não cessa de proteger e manter à distância sua verdade".

Certos traços são notados como artificiais, como na voz, cuja entonação permanece, em alguns autistas, com poucas variações. Certos objetos, se considerados pela criança como um ser vivo, podem converter-se em um duplo. Um exemplo é a televisão, que traz uma série de palavras acopladas a imagens sem que haja a figura do enunciador. Isto denotaria menos incômodo para alguns autistas, pois da televisão provinham inúmeros fragmentos de palavras dos quais eles poderiam se apropriar sem que esteja evidente o desejo do Outro, fator insuportável para muitos.

Em outros contextos, o duplo pode ser uma personagem de histórias e filmes da qual a criança se apropria de modo que passa a se comportar de forma similar a este, apresentando também ecolalias que fazem referência à figura escolhida. É possível que o duplo possa ser construído pelo próprio sujeito, ou seja, composto de uma combinação específica e peculiar: suas características, hábitos e modo de enunciação não inspirado em uma personagem já concluída.

Embora tal fenômeno demonstre certa aproximação com o chamado transtorno das personalidades múltiplas — ou com o que pode ser observado com mais 
frequência em alguns esquizofrênicos que têm certeza de serem personagens históricos, pessoas influentes da sociedade etc. — há uma diferença marcante, pois, para o autista, é essencial conservar o domínio de seu duplo, ou seja, a capacidade de afastar-se ou não, mantendo-o ao seu alcance.

Maleval (2009/2011, p. 104) aponta ainda que a utilização do duplo também possui certos limites, pois “(...) não permite enodar a linguagem com o gozo, de modo que, através do mesmo, o sujeito não sente que consiga conectar-se com o que sente". Conectar-se com o que é sentido e torná-lo acessível aos outros é de todo insuportável no que se refere ao autismo. No entanto, o duplo pode ser este suporte de enunciação que torna possível ao autista "falar por procuração" e, desse modo, proteger-se do desejo do Outro.

Maleval afirma ainda:

Demarcar o gozo não é cifrá-lo mediante o significante. Este último produz uma divisão entre o sujeito do enunciado e o sujeito da enunciação, permitindo ao mesmo tempo a representação do Um no Outro mediante a qual o sujeito sente que fala em nome próprio. Mas essa divisão implica uma perda de controle que o sujeito autista experimenta como angustiante. (MALEVAL, 2009/2011, p. 114)

Segundo o autor, a enunciação desviada e suportada por um duplo não é o único meio do qual o autista se utiliza para não habitar sua palavra, pois o mutismo apresenta-se como o mais radical deles. O autor cita exemplos conhecidos na literatura psicanalítica e geral: Temple Grandin, que é apontada por empregar um método complexo como a enunciação técnica, e Donna Williams, cujos companheiros imaginários já mencionados são tidos como suporte de sua angústia não regulada pelo simbólico.

Embora tente defender-se da linguagem, o autista está de fato imerso nela; e isso o afeta. A construção de uma realidade que possa ser compartilhada com os demais passa por integrá-lo à sua borda para que, a seu modo e com as possibilidades que lhe são peculiares, ele possa esboçar de outras maneiras sua experiência com os elementos que o cercam, suas possíveis desordens e mutabilidades.

\section{CONSIDERAÇÕES FINAIS}

Em Freud, podemos analisar a ambivalência que a palavra Heimlich adquire ao longo do tempo em diversas línguas, cujo significado se confunde, por vezes, com seu oposto Unheimlich. Também foi possível destacar que impressões inicialmente estão associadas ao que figura como estranho até chegarmos à noção de duplo.

A indicação de que Olímpia, a boneca, tenha sido no conto O homem da areia um desprendimento de Natanael - tanto que este lhe devota um amor sem 
restrições, narcisismo primário — também nos é esclarecedor no que se refere ao processo pelo qual o eu é constituído.

A constituição subjetiva e suas implicações também são pontos de análise no texto freudiano e apontam para aspectos relevantes de nosso estudo, tais como a importância do duplo na formação do eu e como uma forma de recusa ao aniquilamento subjetivo. Se, por um lado, o duplo se apresenta como fundamental na constituição do eu — que vemos em Lacan com o estádio do espelho — por outro lado seria um mecanismo de recusa frente ao possível despedaçamento do eu e apaziguamento da angústia não regulada pelo simbólico.

Podemos, com Maleval, deslocar essa noção em Freud, relacionando-a ao autismo. Embora possua limites, por não substituir plenamente o que o ciframento significante do gozo acarretaria, a noção de duplo apresenta-se como um suporte de enunciação que é, ao mesmo tempo, captador de gozo e uma forma consistente. Possibilita uma enunciação artificial com a qual o sujeito pode esboçar formas de laço social na medida em que respeita as defesas autísticas, que visam protegê-lo em relação ao mundo sentido como invasivo.

É importante ferramenta na clínica de autistas, pois pode facilitar o desenvolvimento de estratégias do próprio autista que o auxiliem a transitar entre os diversos espaços e ter acesso a possibilidades de convívio, de forma segura para eles e segundo as particularidades que apresentam.

Desse modo, o duplo apresenta-se como uma tentativa de esboço do campo do Outro, ainda que problemático e por vezes falho. Permite alternativas de enunciação suportáveis, de apaziguamento da angústia frente ao despedaçamento do gozo e à falta decorrente do equívoco da linguagem. Frente a posicionamentos que visam reduzir as potencialidades dos autistas a meros empecilhos para sua socialização - abstendo-os de seus objetos, interesses e habilidades - é necessária a clareza de que tais potencialidades dizem do modo como o sujeito se posiciona no mundo, como ele lida com o desejo do Outro e com a linguagem.

Utilizar-se do que o sujeito autista traz como seu interesse e ampliar as possibilidades presentes nos elementos importantes para ele (facilitando, assim, o processo de "invenção" de outros modos de subjetivação), além de proporcionar abordagens pedagogicamente mais promissoras no tocante à aprendizagem de conteúdos curriculares ou não, de modo que proporcionem o desenvolvimento de habilidades, entre elas a utilização do duplo, ainda que inicialmente, é uma das indicações coerentes com o referencial adotado. Afinal, supor uma enunciação a partir do que muitas vezes está no puro real, de modo que um sujeito possa advir, é uma das ações às quais a psicanálise é chamada a contribuir.

Citações retiradas da edição Amorrortu (tradução nossa).

Recebido em: 13 de julho de 2014. Aprovado em: 11 de janeiro de 2015. 


\title{
REFERÊNCIASS
}

ALLOUCH, Eliane.As psicopatologias do apoio: autismo, adicção, somatização. Ágora: Rio de Janeiro, 2003. V. 6,n.1. Disponível em: $<$ http://www.scielo.br/scielo.php?script=sci_arttext\&pid $=$ S1516$-14982003000100005 \& \operatorname{lng}=p t \& n r m=i s s o>$. Acesso em: 13 dez 2013. FREUD, S. Obras Completas. Standard Edition. Tradução de José L. Etcheverry. Buenos Aires: Amorrortu Editores, 1975. (José L. Etcheverry Trad.). Introducción del narcisismo (1914). V. 14.

Obras Completas. Standard Edition. Tradução de José L. Etcheverry. Buenos Aires: Amorrortu Editores, 1986. (José L. Etcheverry Trad.). Lo ominoso (1919). V. 17.

Obras Completas. Standard Edition. Tradução de José L. Etcheverry. Buenos Aires: Amorrortu Editores, 1992. El yo y el ello (1923). V. 19. HOFFMAN, E. T. A. O homem da areia (1815/1978). Disponível em: <http:// portugues.free-ebooks.net/ebook/O-homem-da-areia/pdf/view>. Acesso em: 19 abr 2013.

MALEVAL, J. C.El altista y su voz (2009). Tradução de Enric Berenguer. Madrid: Editorial Gredos, 2011.

O que existe de constante no autismo? In: CliniCAPS: impasses da clínica. 2010. V. 4, n. 11. Disponível em:<http://www.clinicaps.com. br>. Acesso em: 13 dez 2013.

\author{
Ana Ramyres Andrade de Araújo \\ anaramyresandrade@gmail.com \\ Luis Achiles Rodrigues Furtado \\ luis.achilles@gmail.com \\ Samara Fernandes Paiva dos Santos \\ samarafernandes.psico@yahoo.com.br
}

